\title{
The impact of migration on deaths and hospital admissions from work-related injuries in Australia
}

\author{
Alison Reid, ${ }^{1}$ Susan Peters,${ }^{2}$ Nieves Felipe, ${ }^{3}$ Erik Lenguerrand ${ }^{4}$ Seeromanie Harding ${ }^{4}$
}

oft he global migrant population in 2010 was estimated to be 214 million ( $3 \%$ of the world's population). ${ }^{1}$ Most migrants cross borders to seek better social and economic opportunities and labour mobility has increased with globalisation. An increasingly ageing population and workforce demand in receiving countries suggests that the need for migrant workers in those countries will not decline in the near future. ${ }^{2}$ Several countries choose to recruit more skilled workers. In 2005/06, one-third of all recent immigrants to Organisation for Economic Co-operation and Development (OECD) member countries were tertiary educated. ${ }^{3}$

Australia's migrant intake has mirrored the country's industrial and economic development. Nearly six million European migrants arrived in the post-war period up until the 1960s, making a significant contribution to building Australia's manufacturing industries and infrastructure. As the country transitioned in the mid1970s from a manufacturing and industrial economy to a service-based one, migrants with increased skill and educational levels were sought and it became increasingly difficult to come to Australia as an unskilled worker without family sponsorship. ${ }^{4}$ The requirement for skilled workers tightened further in the mid-1990s. Professionals are now the largest group of recent migrants (40\%) followed by technicians and trade workers (19\%). In 2008, skilled migrants to Australia came from 180 countries, mainly from the UK, India, China and South Africa. ${ }^{5}$

Every year, more than 2.3 million workers globally die from a work-related injury or

\begin{abstract}
Objective: The shift from an industrial to a service-based economy has seen a decline in workrelated injuries (WRIs) and mortality. How this relates to migrant workers, who traditionally held high-risk jobs is unknown. This study examined deaths and hospital admissions from WRI, among foreign and Australian-born workers.

Methods: Tabulated population data from the 1991 to 2011 censuses, national deaths 1991-2002 and hospital admission for 2001-10. Direct age standardised mortality and hospital admission rates (DSRs) and rate ratios (RRs) were derived to examine differences in workrelated mortality/hospital admissions by gender, country of birth, employment skill level and years of residence in Australia.

Results: DSRs and RRs were generally lower or no different between Australian and foreignborn workers. Among men, mortality DSRs were lower for nine of 16 country of birth groups, and hospital admissions DSRs for 14 groups. An exception was New Zealand-born men, with $9 \%(95 \% \mathrm{Cl} 9-13)$ excess mortality and $24 \%(95 \% \mathrm{Cl} 22-26)$ excess hospital admissions.

Conclusions: Four decades ago, foreign-born workers were generally at higher risk of WRI than Australian-born. This pattern has reversed. The local-born comprise $75 \%$ of the population and a pro-active approach to health and safety regulation could achieve large benefits.

Key words: work-related injury fatalities, migrants, country of birth, Australia
\end{abstract}

disease and 317 million accidents occur at work. ${ }^{6}$ Work health and safety legislation and practice differ widely between countries and the heavy burden of accidents and deaths tends to fall on workers in developing countries, where large numbers are employed in the high-risk industries of agriculture, fishing and mining. ${ }^{6}$ Australian states and territories began developing their own occupational health and safety legislation in the 1970s and enacting this legislation from the mid-1980s. ${ }^{7}$ The transition of workers from high-risk industries to the service industry occurred from the 1970s in Australia. During the same time period, road traffic fatalities - estimated to be the cause of up to $30 \%$ of all work-related deaths in Australia ${ }^{8}$ declined markedly. ${ }^{9}$ These factors, and the shift from manual work to automation, has led to a reduction of workers in hazardous conditions and in work-related injuries (WRI) and work-related mortality (WRM). ${ }^{7}$ The work-related injury mortality rate in Australia in 1982-84 was 8.06 per 100,000; 12.05 for men and 1.34 for women..$^{10}$ It declined to 3.8 per 100,000 ( 8.9 for men and 0.7 for women) between $1989-92^{11}$ and to 1.93 per 100,000 ( 3.26 for men and 0.33 for women) in $2010-11 .^{12}$

Deindustrialisation was associated with a $10-15 \%$ decline in the incidence of workrelated injury mortality in the US between 1980 to $1996 .{ }^{13}$ Yet as WRM for US workers overall reduced between 1996 and 2001, it increased among foreign-born workers from

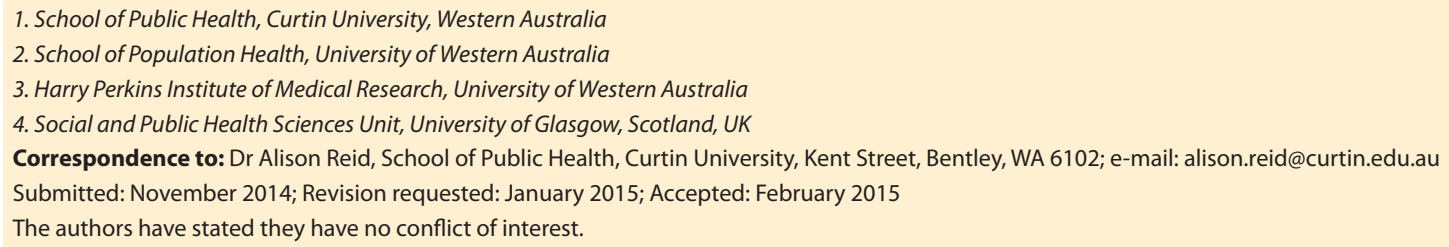


4.3 in 1998 to 5.7 per 100,000 employed workers in $2001 .{ }^{14}$ Similarly, Latino immigrants working in non-agricultural jobs reported a WRI rate that was almost twofold that of the US-born rate. ${ }^{15}$ Higher work-related fatalities and injuries in migrant workers have been reported in several other countries, suggesting that migrant workers are likely to be overrepresented in jobs that involve a high risk of injury. ${ }^{16}$ In Canada, foreign-born men in their first five years of residence had an increased risk of WRI requiring medical treatment compared with the Canadian-born population. ${ }^{17}$ Similarly, WRIs were twice as likely among foreign-born than local-born workers in Germany, the Netherlands, Switzerland and France. ${ }^{16}$ In Australia, overall WRM among foreign-born workers were similar to those of Australian-born workers between 1982 and $1984 .{ }^{18}$ However foreignborn workers from non-English speaking countries, e.g. Italy, Greece and Germany, working in mining and rural occupations had higher WRM than Australian-born workers, but a general convergence toward the Australian rate was observed with increasing length of residence. This study aimed to examine trends in WRM and in hospital admissions due to WRIs among foreign and Australian-born workers over the past two decades.

\section{Methods}

\section{Data sources}

This study used national censuses to assess the population at risk, and deaths records and hospital admissions records to determine work-related injuries and deaths. Use of the data sources was limited by potential disclosure but across all three sources we obtained or derived similar categories of age groups, country of birth groupings and length of residence.

\section{Census data}

The population at risk of WRI was derived from the 1991, 1996, 2001, 2006 and 2011 censuses. Tabulated population data were provided by the Australian Bureau of Statistics (ABS). At each census the following country birth groupings were used: Australia, United Kingdom and Ireland, New Zealand, Italy, Greece, Germany, Vietnam, India and Sri Lanka, China, Malaysia, the Philippines, South Africa; or region of birth: Americas, North Africa and the Middle East, Southern and Eastern Europe, Sub-Saharan Africa and All other countries. In some of the analyses, these were further aggregated due to potential disclosure: Australia; NZ; UK and Ireland; Europe main land (Southern and Eastern Europe, Italy, Germany and Greece); Americas; Asia (Vietnam, India and Sri Lanka, China, Philippines, Malaysia); North Africa and the Middle East and Southern Africa and all other countries (South Africa, Sub-Saharan Africa, all other countries). Age was classified in five-year groups (15-24, 2-34, 35-44, 45-54, 55-64), and length of residence in Australia as 0-10 years or $11+$ years.

Occupational Skill level was aggregated as per the Australian Standard Classification of Occupations (ASCO) $2^{\text {nd }}$ Edition ${ }^{19}$ for the 1991-2001 Census as: Skill Level 1: Managers and Administrators and Professionals; Skill Level 2: Associate Professionals; Skill Level 3: Tradespersons and related workers and advanced clerical and service workers; Skill Level 4: Intermediate clerical, sales and service workers and intermediate production and transport workers; and Skill Level 5: Elementary clerical, sales and service and labourers and related workers. Because of small numbers, skill levels $1-2$ and $4-5$ were combined (see Supplementary table, available online).

\section{Death records}

Anonymised individual-level death records were obtained from the $A B S$, for the period 1991 and 2002. Information on occupation ceased to be recorded on death certificates thereafter (see Supplementary table, available online).

The main and contributing causes of death were classified by the ABS according to the International Classification of Diseases (ICD) volumes ICD-9 (1979-1998) ${ }^{20}$ and ICD-10 (1998-2002). ${ }^{21}$ Work-related fatalities were identified from the External codes (E800E999) from ICD-9 and Chapters V W, $X$ and $Y$ from ICD-10, where a cause of death that was classified as occurring in a workplace, e.g. farm, mine and quarry, industrial place and premises, or ICD-10 trade and service area, industrial and construction area and farm, was included as a WRM. Other E-codes that identified deaths specific to workers were also included, e.g. from ICD-9 E831.2: accident to watercraft causing other injury - occupation of other watercraft - $\mathrm{Crew}^{20}$ and from ICD-10 V 83.0: occupant of special vehicle mainly used on industrial premises injured in transport accident - driver of special industrial vehicle injured in traffic accident. ${ }^{21}$ Any death coded as 'working for income' or 'other work' in the activity code on the death certificate, available from 1998 onwards (ICD-10) was included as a WRM. Other variables available on the death records included country of birth, gender, date of birth, date of death and length of residence in Australia in years.

\section{Hospital admissions data}

The Australian Institute for Health and Welfare (AlHW) provided anonymised individual level hospital admission records for any WRI that was paid for by workers' compensation for the period of financial year 2001/02 to 2009/10. The data provided were by gender and country of birth groupings as per the census records. The data was also aggregated by age (15-24, 25-34, 35-44, 45-54 and 55-64 years).

\section{Statistical analysis}

The censuses provided only a snapshot of the population at the 1991, 1996, 2001, 2006 and 2011 censuses, while the mortality and hospital admissions were continually recorded. Annual estimation of the population at risk was derived using linear interpolation applied to population totals in consecutive censuses. Deaths, hospital admissions and population at risk were then summed over five-year periods due to small numbers of events.

Gender-specific WRM rates and hospital admission rates by country of birth were directly standardised (DSR) using the age structure of the World Standard Population ${ }^{22}$ to allow the examination of absolute country differences in WRM.

Negative binomial regressions were used to compare the country-specific WRM rates of the foreign-born workers with those of Australian-born workers, and to account for over dispersion. The regression models were stratified by gender and adjusted for age, census period and employment skill level. The same approach was used to compare hospital admission rates but the models were adjusted for only age and census period. The effect of length of residence among foreignborn workers was examined using the rates of Australian-born workers as the reference category.

\section{Results}

There were 5,156 WRM between 1991 and 2002 and 659,563 hospital admissions between 2001 and 2010 due to a workrelated injury or illness. Death rates and hospital admission rates were far higher in 
men than women (Table 1).

Among men, death rates were lower for nine country of birth groupings than for those born in Australia. Men born in UK and Ireland, Southern and Eastern Europe, North Africa and the Middle East, Vietnam, Americas, India and Sri Lanka, Malaysia, South African and Sub-Saharan Africa all had lower rates. There was a consistent pattern of lower admission rates for all groups except for those born in NZ. The lowest rates were observed for Vietnam, China and Malaysia.

Among women, death rates did not differ significantly and small numbers of deaths may have limited significance for the generally low mortality pattern. Hospital admissions were less likely for 12 country or region of birth groupings than for those born in Australia. The rates were higher for those born in the UK and Ireland, and in NZ. The lowest rates were for those born in Vietnam, China and Malaysia (Table 1).

Table 2 shows the distributions by skill level and country of birth grouping. In 2001, compared with the Australian-born, the proportion in the top employment skill level was either similar or higher for 10 of 17 country of birth groupings among males, 9 among females. At both Census points, workers from the Philippines had the most disadvantaged distribution. Only small changes occurred in employment skill level among Australian, NZ, Indian and Sri Lankan, Philippines and Sub-Saharan African-born men over the period 1991 and 2001. In contrast, among men born in China, $16 \%$ more were working in employment skill level 1 occupations in 2001 compared with 1991. Similar - although not as marked - increases were also observed among men born in Germany, Greece, Italy and Vietnam. Among women, there were marked increases in those employed in employment skill level 1 occupations between 1991 and 2001 in all country of birth groupings (Table 2).

Figure 1 shows mortality rate ratios (MRRs) adjusted for census time point, employment skill level and age, by regional groupings (a higher level aggregation due to potential disclosure). Adjusted MRRs among men were significantly lower among workers born elsewhere than those born in Australia (Figure 1). Among women, the confidence intervals were wide, reflecting imprecision of the MRRs, but lower MRRs for those from Europe mainland and Asia were of borderline significance. For both men and women, the time trend reflected general improvement

Table 1: Directly standardised work-related mortality and hospital admission rates per 100,000 for males and females by country of birth, 1991-2002 (mortality) and 2001-2010 (morbidity), Australia.

\begin{tabular}{|c|c|c|c|c|c|c|}
\hline \multirow[b]{2}{*}{$\begin{array}{l}\text { Country/Region } \\
\text { of birth }\end{array}$} & \multicolumn{3}{|c|}{ Mortality (1991-2002) } & \multicolumn{3}{|c|}{ Morbidity (2001-2010) } \\
\hline & $\begin{array}{c}\mathrm{N} \\
\text { Fatalities }\end{array}$ & $\begin{array}{l}\text { Person } \\
\text { years }\end{array}$ & DSR $(95 \% \mathrm{Cl})$ & $\begin{array}{l}\text { NHospital } \\
\text { admissions }\end{array}$ & $\begin{array}{l}\text { Person } \\
\text { years }\end{array}$ & DSR $(95 \% \mathrm{Cl})$ \\
\hline \multicolumn{7}{|l|}{ Males } \\
\hline Australia & 3,489 & $50,213,390$ & $6.97(6.74-7.20)$ & 366,031 & $27,653,171$ & $1,333.29(1,328.97-1,337.62)$ \\
\hline UK \& Ireland & 265 & $4,886,981$ & $5.60(4.76-6.60)$ & 28,482 & $2,404,641$ & $1,132.85(1,116.72-1,149.22)$ \\
\hline $\begin{array}{l}\text { Southern \& Eastern } \\
\text { Europe }\end{array}$ & 112 & $1,888,993$ & $4.28(3.41-5.51)$ & 12,341 & 956,168 & $1,156.78(1,132.7-1,181.35)$ \\
\hline New Zealand & 115 & $1,496,619$ & $7.27(5.95-8.85)$ & 15,564 & 907,575 & $1,682.62(1,656-1,709.57)$ \\
\hline $\begin{array}{l}\text { North Africa \& the } \\
\text { Middle East }\end{array}$ & 31 & 992,477 & $3.08(1.99-4.72)$ & 6,547 & 596,831 & $1,077.67(1,051.01-1,104.89)$ \\
\hline Italy & 56 & 972,546 & $4.34(2.85-10.3)$ & 5,268 & 411,268 & $1,088.11(1,026.6-1,154.23)$ \\
\hline Vietnam & 28 & 749,037 & $4.42(2.83-6.73)$ & 2,216 & 398,822 & $528.22(505.71-551.62)$ \\
\hline Americas & 26 & 709,580 & $3.53(2.26-5.37)$ & 4,635 & 410,555 & $1,096.26(1,064.54,1-128.73)$ \\
\hline India \& Sri Lanka & 13 & 622,787 & $2.42(1.22-4.49)$ & 3,916 & 479,974 & 817.47 (792.04-843.53) \\
\hline Greece & 29 & 566,238 & $3.65(2.08-10.6)$ & 2,104 & 239,764 & $813.96(751.44-882.52)$ \\
\hline China & 27 & 513,706 & $5.86(3.63-9.22)$ & 1,399 & 393,535 & $344.39(326.35-363.19)$ \\
\hline Germany & 36 & 496,993 & $7.18(3.86-13.5)$ & 2,363 & 239,445 & $895.67(844.46-950.05)$ \\
\hline Philippines & 13 & 286,990 & $4.46(2.17-9.06)$ & 1,698 & 194,274 & $879.2(836.52-923.87)$ \\
\hline Malaysia & 9 & 364,721 & $2.35(1.07-4.77)$ & 851 & 207,446 & $416.23(388.62-445.36)$ \\
\hline South Africa & 9 & 285,267 & $2.89(1.29-5.78)$ & 1,768 & 214,635 & $801.05(763.91-839.61)$ \\
\hline Sub-Saharan Africa & 8 & 275,432 & $2.55(1.01-5.86)$ & 2,061 & 189,255 & $1,042.8(997.33-1,089.92)$ \\
\hline All other countries & 160 & $2,741,638$ & $5.60(4.76-6.56)$ & 28,457 & $1,631,587$ & $1,731.93(1,711.78-1,752.26)$ \\
\hline All foreign-born & 937 & $17,850,006$ & $5.03(4.68-5.40)$ & 119,670 & $9,875,775$ & $1,169.57(1,162.59-1,176.58)$ \\
\hline \multicolumn{7}{|l|}{ Females } \\
\hline Australia & 545 & $50,697,763$ & $1.09(1.00-1.18)$ & 127,804 & $28,211,821$ & $463.14(460.6-465.69)$ \\
\hline UK \& Ireland & 62 & $4,643,013$ & $1.17(0.82-1.69)$ & 12,785 & $2,313,117$ & $488.35(478.38-498.53)$ \\
\hline $\begin{array}{l}\text { Southern \& Eastern } \\
\text { Europe }\end{array}$ & 15 & $1,761,235$ & $0.88(0.39-1.89)$ & 4,997 & 951,970 & $439.33(426.04-453.06)$ \\
\hline New Zealand & 14 & $1,443,694$ & $1.16(0.62-2.02)$ & 4,472 & 889,959 & $491.06(476.65-505.82)$ \\
\hline $\begin{array}{l}\text { North Africa \& the } \\
\text { Middle East }\end{array}$ & 4 & 875,890 & $0.40(0.11-1.34)$ & 1,537 & 532,462 & $269.52(256.09-283.51)$ \\
\hline Italy & 17 & 857,613 & $0.84(0.47-8.05)$ & 1,543 & 376,601 & $344.48(313.88-380.31)$ \\
\hline Vietnam & 6 & 749,337 & $0.98(0.32-2.41)$ & 670 & 437,107 & $150.53(139.04-162.86)$ \\
\hline Americas & 7 & 733,830 & $0.75(0.30-1.81)$ & 2,065 & 437,524 & $450.9(431.53-470.97)$ \\
\hline India \& Sri Lanka & 3 & 565,057 & $0.71(0.11-2.62)$ & 1,410 & 408,044 & $334.56(317.23-352.62)$ \\
\hline Greece & 2 & 558,813 & $0.27(0.03-8.08)$ & 1,054 & 246,671 & $370.63(335.82-411.29)$ \\
\hline China & 6 & 537,678 & $1.29(0.41-3.44)$ & 633 & 470,048 & $140.9(129.98-152.53)$ \\
\hline Germany & 9 & 471,239 & $1.35(0.50-5.58)$ & 961 & 237,063 & $342.57(315-372.72)$ \\
\hline Philippines & 2 & 597,417 & $0.50(0.05-2.13)$ & 1,692 & 382,548 & $402.33(382-61,422.9)$ \\
\hline Malaysia & 2 & 416,768 & $0.43(0.05-2.10)$ & 525 & 247,180 & $207.55(190.04-226.3)$ \\
\hline South Africa & 2 & 292,313 & $0.75(0.08-2.98)$ & 697 & 221,616 & $310.7(287.94-334.84)$ \\
\hline Sub-Saharan Africa & 2 & 262,732 & $1.31(0.16-4.73)$ & 773 & 184,989 & $410.16(381.37-440.7)$ \\
\hline All other countries & 32 & $2,869,573$ & $1.11(0.76-1.59)$ & 10,244 & $1,792,520$ & $565.58(554.68-576.65)$ \\
\hline All foreign-born & 185 & $17,636,201$ & $0.99(0.84-1.17)$ & 46,058 & $10,129,419$ & $413.83(409.94-417.76)$ \\
\hline
\end{tabular}

in WRM over time, irrespective of region or country of birth, age and employment skill level, (MRR 0.90, 95\%Cl 0.89-0.91 and MMR $0.83,95 \% \mathrm{Cl} 0.81-0.86$ ) respectively.

Table 3 shows MRRs (death rate for Australian born as the reference) by duration of residence among men. Apart from NZers who had lived in Australia for less than 11 years, there was a broad pattern of lower mortality for most regional grouping, regardless of length of residence. The small number of deaths among most of the groups for women prevented any reliable interpretation (data not shown). The only notable results were for women from the United Kingdom and Ireland. MRRs for those who had been resident for more than 11 years were lower (MRR 0.71, $95 \% \mathrm{Cl} 0.50-99, \mathrm{n}=37$ ), and not significant for those who had lived there for fewer years (MRR 2.17, 95\% Cl 0.49-3.63, $\mathrm{n}=15$ ). 
Figure 1: Mortality rate ratios for deaths from work-related injuries by region of birth and sex, adjusted for age, census time point and employment skill level.

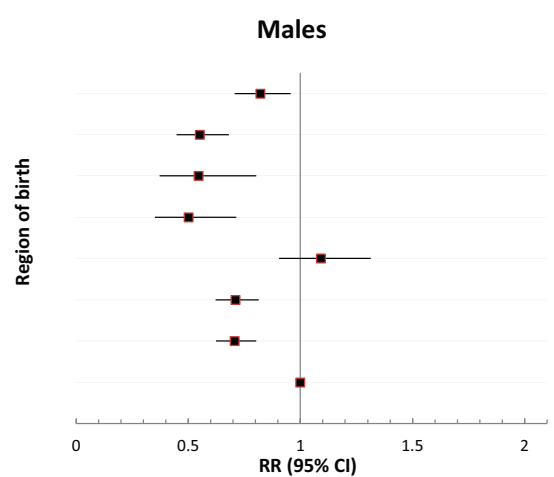

Females

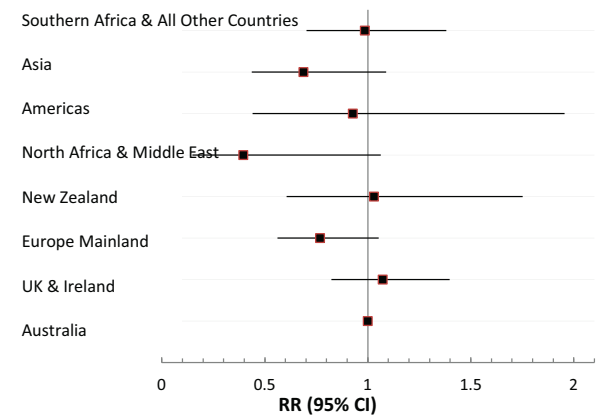

Table 2. Change in employment skill level+ between 1991 and 2001 for males and females by country or region of birth.

\begin{tabular}{|c|c|c|c|c|c|}
\hline & \multirow{2}{*}{ Skill level } & \multicolumn{2}{|c|}{ Males } & \multicolumn{2}{|c|}{ Females } \\
\hline & & $1991 \%$ & Difference & $1991 \%$ & Difference \\
\hline \multirow[t]{2}{*}{ Australia } & 1 & 37.8 & $+2.1 \%$ & 33.3 & $+5.8 \%$ \\
\hline & 3 & 39.9 & $-1.6 \%$ & 59.3 & $-8.8 \%$ \\
\hline \multirow[t]{2}{*}{ UK \& Ireland } & 1 & 42.5 & $+5.7 \%$ & 35.3 & $+8.6 \%$ \\
\hline & 3 & 34.8 & $-3.7 \%$ & 57.5 & $-12.2 \%$ \\
\hline \multirow[t]{2}{*}{ South \& East Europe } & 1 & 24.4 & $+5.9 \%$ & 23.1 & $+8.2 \%$ \\
\hline & 3 & 46.3 & $-3.1 \%$ & 69.4 & $-10.5 \%$ \\
\hline \multirow[t]{2}{*}{ New Zealand } & 1 & 33.7 & $+2.8 \%$ & 32.0 & $+6.6 \%$ \\
\hline & 3 & 42.5 & $-0.4 \%$ & 60.3 & $-9.1 \%$ \\
\hline \multirow[t]{2}{*}{ N Africa \& Mid East } & 1 & 33.5 & $+5.1 \%$ & 29.4 & $+8.9 \%$ \\
\hline & 3 & 46.4 & $-4.4 \%$ & 63.3 & $-12.2 \%$ \\
\hline \multirow[t]{2}{*}{ Italy } & 1 & 27.5 & $+7.5 \%$ & 22.4 & $+6.5 \%$ \\
\hline & 3 & 42.6 & $-5.9 \%$ & 66.9 & $-11.3 \%$ \\
\hline \multirow[t]{2}{*}{ Vietnam } & 1 & 21.8 & $+9.1 \%$ & 19.1 & $+10.9 \%$ \\
\hline & 3 & 59.0 & $-6.9 \%$ & 71.1 & $-10.2 \%$ \\
\hline \multirow[t]{2}{*}{ Americas } & 1 & 44.6 & $+4.7 \%$ & 43.1 & $+4.3 \%$ \\
\hline & 3 & 36.6 & $-2.4 \%$ & 50.9 & $-6.3 \%$ \\
\hline \multirow[t]{2}{*}{ India \& Sri Lanka } & 1 & 49.7 & $+2.6 \%$ & 33.6 & $+8.1 \%$ \\
\hline & 3 & 37.6 & $+0.1 \%$ & 59.8 & $-9.9 \%$ \\
\hline \multirow[t]{2}{*}{ Greece } & 1 & 24.1 & $+8.9 \%$ & 19.6 & $+9.8 \%$ \\
\hline & 3 & 53.5 & $-8.9 \%$ & 72.7 & $-13.2 \%$ \\
\hline \multirow[t]{2}{*}{ China } & 1 & 30.2 & $+16.0 \%$ & 25.0 & $+13.6 \%$ \\
\hline & 3 & 43.8 & $-8.5 \%$ & 66.7 & $-13.8 \%$ \\
\hline \multirow[t]{2}{*}{ Germany } & 1 & 40.8 & $+6.2 \%$ & 35.2 & $+8.7 \%$ \\
\hline & 3 & 30.3 & $-0.9 \%$ & 56.0 & $-11.7 \%$ \\
\hline \multirow[t]{2}{*}{ Philippines } & 1 & 24.7 & $+3.5 \%$ & 23.5 & $+3.3 \%$ \\
\hline & 3 & 56.8 & $-1.7 \%$ & 71.7 & $-4.7 \%$ \\
\hline \multirow[t]{2}{*}{ Malaysia } & 1 & 59.8 & $+5.6 \%$ & 51.2 & $+6.5 \%$ \\
\hline & 3 & 29.0 & $-3.5 \%$ & 43.5 & $-8.7 \%$ \\
\hline \multirow[t]{2}{*}{ South Africa } & 1 & 56.2 & $+6.0 \%$ & 42.1 & $+10.0 \%$ \\
\hline & 3 & 25.4 & $-3.7 \%$ & 50.6 & $-13.1 \%$ \\
\hline \multirow[t]{2}{*}{ Sub-Saharan Africa } & 1 & 44.8 & $+3.9 \%$ & 34.6 & $+7.6 \%$ \\
\hline & 3 & 39.7 & $-2.1 \%$ & 58.7 & $-10.9 \%$ \\
\hline \multirow[t]{2}{*}{ All other Countries } & 1 & 39.9 & $+4.9 \%$ & 36.5 & $+3.9 \%$ \\
\hline & 3 & 38.6 & $0 \%$ & 56.3 & $-5.9 \%$ \\
\hline \multicolumn{5}{|c|}{$\begin{array}{l}\text { +Employment Skill Level coded from the Australian Standard Classification of Occupations 2nd Edition (ASCO). } \\
1=\text { Managers and Administrators, Professionals and Associate Professionals. }\end{array}$} & \\
\hline
\end{tabular}

The pattern of lower hospital admission rates among men for all country or region of birth groupings compared with Australian-born workers remained the same after adjusting for age and census time point (Figure 2).

These adjustments did not remove the excess hospital admissions for NZ men or those born in 'All Other Countries.' The lowest rate ratios were observed for workers born in China, Vietnam and Malaysia. The pattern was similar for women although women born in 'All Other Countries', NZ and the United Kingdom and Ireland had higher rate ratios for hospital admission. The lowest rate ratios were observed for workers born in China, Vietnam and Malaysia. For both men and women, adjusted for region of birth and age, the risk of admissions for a WRI increased across time (RR 1.324, 95\%Cl 1.323-1.326 and RR 1.323, 95\% Cl1.321-1.326), respectively.

\section{Discussion}

This study is the first examination of deaths and hospital admissions due to WRI among foreign and Australian-born workers after the transition to a service-based economy and the consequent demand for more skilled migration. A consistent pattern was lower mortality and likelihood of hospital admissions for foreign-born workers, including workers from countries historically thought to be at greater risk. For example, both men and women from the Eastern Asian countries had lower hospital admissions than Australian-born workers. Men from NZ, on the other hand, appeared to be at greater risk of hospital admissions due to WRI. Overall, the rates of WRM fell in Australia from the 1990s.

Studies from other countries have found disparities in fatal ${ }^{23-26}$ and non-fatal workrelated injuries $15,17,27,28$ among migrants compared with native-born populations, in contrast to this current study. In those other studies, migrants or foreign-born workers tended to work in agriculture and construction and were often temporary and unskilled workers. ${ }^{15,24,28}$ This is not the case in Australia. From the 1970s, it became increasingly difficult for unskilled migrants to enter Australia other than on a humanitarian or family reunion basis, ${ }^{4}$ and from the mid-1990s Australia has specifically encouraged skilled migration. ${ }^{29}$ Most migrants to Australia come as permanent migrants. Participation in the labour force (75\%) and unemployment (6.3\%) is higher compared with $68 \%$ and $3.2 \%$ respectively for 
the Australian-born population. ${ }^{30}$ Working in jobs below their qualification level is an issue with $29 \%$ of professionals being employed as professionals in their first job, increasing to $39 \%$ in a subsequent job. ${ }^{5,31}$ Illegal migration is not a significant problem and was estimated to be 60,900 at June 2012.32 Substantial changes in migrant stock to Australia and the industry they work in after arrival may explain why this study did not find an excess risk of WRM.

In this present study, Australian-born workers have higher rates of WRM and WRI than foreign-born workers. The findings correspond with recent analyses of the national multi-purpose household surveys conducted in 2005-06 and 2009-10 that showed higher rates of WRI among Australian-born compared with foreign-born workers. Australian-born workers were more likely to work in agriculture (4.2\% vs. $1.2 \%)$ and construction ( $8.3 \%$ vs. $7.1 \%)$, and less likely to work in the service industry $(46.4 \%$ vs. $48.9 \%$ ) than foreign-born workers. ${ }^{33}$ Transport, agriculture, mining, manufacturing and construction industries consistently have the highest WRM in Australia. ${ }^{34,35}$ Australianborn workers were also more likely to work without paid leave entitlements (17.3\%) than foreign-born workers (16.2\%), but other conditions of shift work, working fixed term or contracts and working longer than 38 hours per week did not differ between Australian or foreign-born workers. ${ }^{33}$ Foreign-born workers who have migrated to Australia as skilled migrants based on their educational qualifications, work experience and skills and English language proficiency are more likely to work in the services (48.9\%), manufacturing (10.8\%) and hospitality (5.9\%) industries compared with Australian-born workers. ${ }^{33} \mathrm{NZ}$ workers were an exception, and their generally greater mortality risks compared to the Australian-born workers might be related to their greater likelihood to work in high-risk industries, such as construction and manufacturing ${ }^{36} \mathrm{NZ}$ males are more likely to work in construction (21\%) and manufacturing (13\%) than the Australian population ( $15 \%$ and $12 \%$ respectively). Of those working in construction $46 \%$, were technicians or trade workers and $28 \%$ were labourers, while those in manufacturing were technician or trade workers (29\%), machinery operators or drivers (20\%), managers (19\%) and labourers (18\%). NZ women tend to work in manufacturing, retail and health care and social assistance. ${ }^{36}$ These occupational disparities may explain why NZers have a 2002 by country or region of birth and duration of residence, adjusted for age, employment skill level and census time point.

Country/Region of birth
Dales
Deaths

Australia $\quad 3,489 \quad 1.00$ (Ref)

UK and Ireland $\quad 34 \quad 0.69(0.50-0.97)$

Europe main land $\quad 150.54(0.32-0.90)$

New Zealand $\quad 54 \quad 1.25(0.95-1.63)$

North Africa and the Middle East $\quad 6 \quad 0.35(0.16-0.78)$

Americas $\quad 90.59(0.31-1.14)$

\begin{tabular}{lll} 
Asia & 51 & 0.64 \\
\hline & $(0.48-0.84)$
\end{tabular}

Southern Africa and all other $\quad 44 \quad 0.57(0.43-0.77)$

Countries

Duration of residence in Australia 11+ years

\begin{tabular}{lrr}
\hline Australia & 3,489 & 1.00 (Ref) \\
\hline UK and Ireland & 231 & $0.71(0.62-0.81)$ \\
\hline Europe main land & 218 & $0.72(0.63-0.83)$ \\
\hline New Zealand & 61 & $0.98(0.76-1.27)$ \\
\hline North Africa and the Middle East & 25 & $0.56(0.38-0.83)$ \\
\hline Americas & 17 & $0.52(0.33-0.84)$ \\
\hline Asia & 39 & $0.47(0.34-0.64)$ \\
\hline $\begin{array}{l}\text { Southern Africa and all other } \\
\text { Countries }\end{array}$ & 133 & $0.95(0.80-1.14)$ \\
\hline
\end{tabular}

higher risk of hospitalisation for work-related injuries and a suggestion of a higher risk of work-related injury fatalities than Australianborn workers. ${ }^{37}$

Australia ranked seventh among 10 European countries and NZ in a comparison of WRM based on data from 1998-99 and 2000-01, after standardising for differences in industrial sector. ${ }^{34}$ Only Belgium and Germany (3.0 per $100,000)$ and NZ $(3.6$ per 100,000) had higher WRM than Australia (2.8 per 100,000). The UK and Sweden had the fewest fatalities at 1.7 per $100,000 .{ }^{34}$ Other work showed higher WRM rates for NZ $(4.9$ per 100,000) compared with Australia (3.8 per 100,000) and the US
Table 3: Mortality rate ratios (MRRs) for males 1991 -
(3.2 per 100,000) ${ }^{38}$ between 1989-92. Our findings suggest that without migration and the attenuating impact of migrant workers on work-related injury statistics, Australia may fare worse internationally in terms of injury rankings.

\section{Limitations and strengths}

A limitation of this study is that in Australia, hospital admissions for work-related injury or illness can only be identified if the payment status for the admission was workers' compensation. Other work has shown that this method of capturing is associated with an underestimate in the number of WRI. For the state of New South Wales, $69 \%$ of all WRI hospital admissions $s^{39,40}$ were identified using this method and undercounting was greater among persons from non-English speaking backgrounds than English speaking, where $60 \%$ and $71 \%$ of hospital admissions for WRI were identified respectively. ${ }^{39}$ Differential access to workers compensation could depress the hospital admissions for WRI among foreign-born compared to Australianborn workers, but this issue has not been examined in Australia., ${ }^{41,42}$

Another limitation refers to the use of death certificates as a source of WRM as Australian death certificates do not specifically identify WRM. We used the External Cause codes in the relevant ICD volumes. The major cause of WRM is traffic accidents, e.g. driving as part of the job and commuting to/from work. Half of all WRM in Australia in 2010-2011 were the result of a traffic incident. ${ }^{43}$ However, we were unable to examine traffic incidents as they are not coded in the ICD volumes if they are work-related or not. There is little information on whether the incidence of traffic fatalities differs by migration status, but Factor et al. (2008) reported an increased risk of
Figure 2: Rate ratios for admissions for work-related injuries by country and region of birth and sex, adjusted for age and census time point.
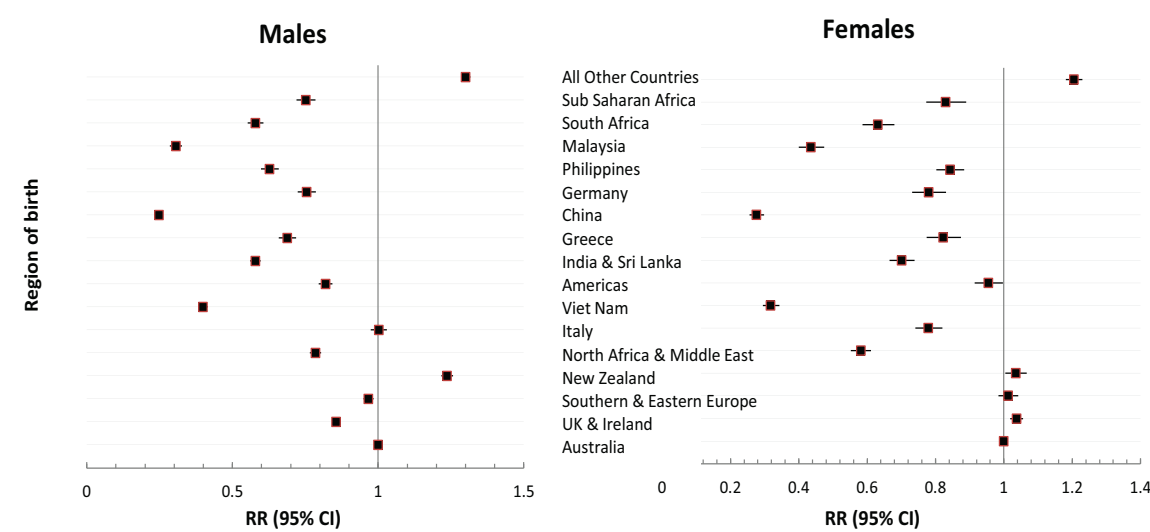
involvement in fatal or severe traffic accidents among people from Africa or Asia compared with Europe or the US. Excluding traffic accidents may have underestimated the risk of WRM among foreign-born workers. ${ }^{44}$

We found that the risk of hospital admission for a work-related injury or illness increased over time in contrast to WRM, which decreased. There are several possible explanations for this disparity. First, hospital admissions data capture all hospital admissions paid for by workers compensation, including illness as well as injury. So admissions for occupational cancers (e.g. mesothelioma) or other work-related illnesses such as asthma would be included in our data. It has been estimated that 5,000 invasive cancers and 34,000 non-melanoma skin cancers per year in Australia are caused by occupational exposure to carcinogens. ${ }^{37}$ In addition, work-related injuries resulting from road traffic accidents will have been included in the hospital admissions data, but not included in the mortality records.

The remainder group 'All other countries' had a greater likelihood of hospital admissions but not of mortality than the Australian-born. We were unable to examine this group in detail due to disclosure. However, further analysis of the 2001 Census showed that $30 \%$ of males from this group worked as tradespersons and related workers and $24 \%$ worked as labourers and related workers, suggesting that they may be working in the more risky occupations. Sixty-two per cent were aged less than 45 years. Among females, $65 \%$ were aged less than 45 years, and $52 \%$ worked as intermediate clerical, sales and service workers and $21 \%$ as labourers.

There are two key strengths of this study. It is based on national data over a 16-year time span, and covers both hospital admissions and mortality from WRIs. It is one of a few studies to examine WRM and hospital admissions among all foreign-born workers across different occupations, not limited to those who work in the high risk industries.

\section{Conclusion}

The rates of WRM have fallen since the 1990s, but Australian-born workers appear to be at a greater risk than foreign-born workers. These findings signal the need to continue to promote occupational health and safety in all industries, and specifically high-risk industries, to further reduce the risk of work- related accidents and injuries to all workers in Australia.

\section{Acknowledgements}

This work was supported by the Australian

Research Council [DP110101012].

\section{References}

1. International Labour Organization. Facts On Labour Migration. Geneva (CHE): ILO; 2006.

2. International Labour Organisation. Report VI:Towards a Fair Deal for Migrant Workers in the Global Economy. Proceedings of the International Labour Conference 92nd Session; 2004; Geneva (CHE): ILO Publications; 2004.

3. Widmaier S, Dumont J. Are Recent Immigrant Different? A New Profile of Immigrants in the OECD based on DIOC 2005/06. OECD Social, Employmentand Migration Working Papers, No.: 126. Paris (FRA): OECD Publishing; 2011

4. Teicher J, Shah C, Griffin G. Australian immigration: the triumph of economics over prejudice? Int J Manpow. 2002;23(3):209-36.

5. Australian Bureau of Statistics. 3416.0 Perspectives on Migrants: Skilled Migration. Canberra (AUST): Canberra (AUST): ABS; 2009.

6. International Labour Organisation. Safety and Health at Work. Geneva (CHE): ILO; 2013 [cited 2013 Aug 2]. Available from: http://www.ilo.org/global/topics/ safety-and-health-at-work/lang--en/index.htm

7. Gruszin S, Hetzel D, Glover J. Advocacy and action in public health: Lessons from Australia over the 20th century. Canberra (AUST): Australian National Preventive Health Agency; 2012.

8. Mitchell R, Driscoll T, Healey S. Work-related road fatalities in Australia. Accid Anal Prev. 2004;36(5):851-60

9. Gargett S, Connelly LB, Nghiem S. Are we there yet? Australian road safety targets and road traffic crash fatalities. BMC Public Health. 2011;11(1):270.

10. Harrison JE, Frommer MS, Ruck EA, Blyth FM. Deaths as a result of work-related injury in Australia, 1982-1984. Med J Aust. 1989;150(3):118-25.

11. National Occupational Health and Safety Commission. Work-related Traumatic Fatalities in Australia, 1989-92. Canberra (AUST): Commonwealthof Australia, 1998.

12. Safe Work Australia. Work-related Traumatic Injury Fatalities, Australia 2010-11. Canberra (AUST): SWA 2012.

13. Loomis D, Richardson DB, Bena JF, Bailer AJ. Deindustrialisation and the long term decline in fatal occupational injuries. Occup Environ Med. 2004;61(7):616-21.

14. Loh K, Richardson S. Foreign-born workers: Trends in fatal occupational injuries, 1996-2001. Mon Labor Rev. 2004;127:42.

15. Pransky G, Moshenberg D, Benjamin K, Portillo S, Thackrey JL, Hill-Fotouhi C. Occupational risks and injuries in non-agricultural immigrant Latino workers. Am JInd Med. 2002:42(2):117-23.

16. Bollini P, Siem H. No real progress towards equity: Health of migrants and ethnic minorities on the eve of theyea 2000. Soc SciMed. 1995;41(6):819-28.

17. Smith PM, Mustard CA. Comparing the risk of work related injuries between immigrants to Canada and Canadian-born labour market participants. Occup Environ Med. 2009;66(6):361-7.

18. Corvalan CF, Driscoll TR, Harrison JE. Role of migrant factors in work-related fatalities in Australia. Scand $J$ Work Environ Health. 1994;20(5):364-70.

19. Australian Bureau of Statistics. Australian Standard Classification of Occupations. 2nd ed. Canberra (AUST): ABS; 1997.

20. World Health Organization. Manual of the International Statistical Classification of Diseases, Injuries, and Causes of Death. Geneva (CHE):WHO; 1977.

21. World Health Organization. International Statistical Classification of Diseases and Related Health Problems. 1989 rev ed. Geneva (CHE):WHO; 1992.
22. National Cancer Institute. Surveillance Epidemiology and End Results: Standard Populations [Internet]. Bethesda (MD): NCl; 2012 [cited 2012 Dec 20]. Available from: http://www.seer.cancer.gov/stdpopulations/ stdpop.19ages.html

23. Ahonen EQ, Benavides FG. Risk of fatal and non-fatal occupational injury in foreign workers in Spain. $J$ Epidemiol Community Health. 2006;60(5):424-6.

24. Dong X, Platner JW. Occupational fatalities of Hispanic construction workers from 1992 to 2000. Am JInd Med. 2004;45(1):45-54.

25. Richardson DB, Loomis D, Bena J, Bailer AJ. Fatal occupational injury rates in southern and non-southern States, by race and Hispanic ethnicity. Am J Public Health. 2004;94(10):1756-61.

26. Sincavage JR. Fatal occupational injuries among Asian workers. Mon Labor Rev. 2005;128(10):49-55.

27. Friedman LS, Forst L. Ethnic disparities in traumatic occupational injury. Int J Occup Environ Med. 2008;50(3):350-8.

28. Salvatore MA, Baglio G, Cacciani L, Spagnolo A, Rosano A. Work-related injuries among immigrant workers in Italy. JImmigr Minor Health. 2013;15(1):182-7.

29. Australian Bureau of Statistics. 3416.0 Perspectives on Migrants: Skilled Migration. Canberra (AUST): ABS; 2011.

30. Australian Bureau of Statistics. 3416.0 - Perspectives on Migrants, 2011. Canberra (AUST): ABS; 2012.

31. Reid A. Under-use of migrants' employment skills linked to poorer mental health. Aust NZJ Public Health. 2012;36(2):120-5.

32. Department of Immigration and Citizenship. Fact Sheet 87 - Initiatives to Combat Illegal Work in Australia. Canberra (AUST): Commnwealth of Australia; 2013.

33. Reid A, Lenguerrand E, Santos I, Read U, LaMontagne $A D$, Fritschi $L$, et al. Taking risks and survival jobs: Foreign-born workers and work-related injuries in Australia. Saf Sci. 2014;70:378-86.

34. National Occupational Health and Safety Commission. FatalOccupational Injuries-HowDoes Australia Compare Internationally? Canberra (AUST): Commonwealth of Australia; 2004.

35. Safe Work Australia. Work-related Traumatic Injury Fatalities, Australia 2009-10. Canberra (AUST): SWA; 2012.

36. Australian Bureau of Statistics. New Zealanders in Australia. Canberra (AUST): ABS; 2011

37. Fritschi L, Driscoll T. Cancer due to occupation in Australia. Aust NZ J Public Health. 2006;30(3):213-9.

38. Feyer AM, Williamson A, Stout $\mathrm{N}$, Driscoll $\mathrm{T}$, Usher $\mathrm{H}$, Langley J. Comparison of work related fatal injuries in the United States, Australia, and New Zealand: method and overall findings. Inj Prev. 2001;7(1):22-8.

39. Mitchell R, McClure R, Driscoll T. Refining estimates of hospitalised work-related injuries in NSW, 2000/01 to 2004/05. J Occup Health Saf Aust NZ. 2008;24(1):33-42.

40. McKenzie K, Mitchell R, Scott DA, Harrison JE, McClure RJ.The reliability of information on work-related injuries available from hospitalisation data in Australia. Aust N ZJ Public Health. 2009;33(4):332-8.

41. Kosny $A$, MacEachen $E$, Lifshen $M$, Smith $P$, Jafri $G J$, Neilson C, et al. Delicate dances: Immigrant workers' experiences of injury reporting and claim filing. Ethn Health. 2012;17(3):267-90.

42. Safe Work Australia. Australian Workers' Compensation Statistics, 2012-13. Canberra (AUST): SWA; 2014.

43. Safe Work Australia. Work-related Traumatic Injury Fatalities, Australia 2009-10. Canberra (AUST): SWA; 2012.

44. Factor R, Mahalel D, Yair G. Inter-group differences in road-traffic crash involvement. Accid Anal Prev. 2008;40(6):2000-7.

\section{Supporting Information}

Additional supporting information may be found in the online version of this article:

Supplementary Table 1: Description of data sources for hospital admissions and deaths from work related injuries and for denominators. 